\title{
Chronic Low-Dose Corticosterone Supplementation Enhances Acquired Epileptogenesis in the Rat Amygdala Kindling Model of TLE
}

\author{
Taufik R Taher', Michael Salzberg ${ }^{2}$, Margaret J Morris ${ }^{3}$, Sandra Rees ${ }^{4}$ and Terence J O'Brien*, ${ }^{*, 5}$ \\ 'The Department of Medicine, The Royal Melbourne Hospital, The University of Melbourne, Parkville, Victoria, Australia; ${ }^{2}$ The Department \\ of Psychiatry, St Vincent's Hospital, Australia; ${ }^{3}$ The Department of Pharmacology, The University of Melbourne, Australia; ${ }^{4}$ The Department \\ of Anatomy, The University of Melbourne, Australia; ${ }^{5}$ The Department of Neurology, The Royal Melbourne Hospital, Australia
}

\begin{abstract}
Mesial temporal lobe epilepsy (MTLE) is associated with high rates of depression and anxiety. A bidirectional causal relationship has been suggested, with these psychiatric comorbidities themselves enhancing epileptogenesis, possibly via hypercortisolemia. We examined the effects on epileptogenesis of chronic supplementation with low-dose corticosterone (CS) in the electrical amygdala kindling rat model. Adult Wistar rats were ovariectomized and implanted with bipolar electrodes into the left amygdala. After I week recovery, one group $(n=7)$ had CS (3 mg/l00 ml-approx. $4.5 \mathrm{mg} / \mathrm{kg} /$ day) and a control group saline $(n=7)$ added to their drinking water, and both groups underwent twice daily electrical stimulations. Rats were culled 2 weeks after reaching the fully kindled state. A stereological optical fractionator technique was used to estimate the number of CAI pyramidal cells in the hippocampus ipsilateral to the stimulations. Fewer stimulations were required in the CS-supplemented rats than in controls to reach the fully kindled state ( 32 vs $81, p<0.03$, Student's $t$-test) and the first Class $\vee$ seizure ( 14 vs 57, $p<0.05)$. The mean after-discharge length was greater in the CS group $(p=0.03$, repeated measures analysis of variance). There was no difference in the mean number of CAI neurons $\left(1.05 \times 10^{5} \mathrm{vs} 1.04 \times 10^{5}, p=0.98\right)$. These data demonstrate that low-dose CS enhances epileptogenesis in this model of MTLE. This provides support for the hypothesis that chronic hypercortisolemia, as a result of stress, anxiety, and/or depression, may facilitate the development and progression of epilepsy in patients with MTLE. The lack of difference in hippocampal CAI neurons indicates that the mechanism does not primarily involve pyramidal cell loss.

Neuropsychopharmacology (2005) 30, I6I0-1616. doi:I0.1038/sj.npp. I300709; published online I6 March 2005
\end{abstract}

Keywords: epileptogenesis; temporal lobe epilepsy; amygdala kindling; corticosterone; stress

\section{INTRODUCTION}

Mesial temporal lobe epilepsy (MTLE) is the most common form of focal epilepsy in adults that is resistant to medical therapy (Engel Jr et al, 1997). High rates of depression and anxiety in individuals with epilepsy have been reported in many studies, with a specific association with MTLE postulated (Barry et al, 2001; Herman and Cullinan, 1997; Lambert and Robertson, 1999; Ring and Trimble, 1993). This association may be due to a combination of neurobiological and psychosocial factors resulting from recurrent seizures. In the 5th century $\mathrm{BC}$, Hippocrates first

\footnotetext{
*Correspondence: Dr TJ O'Brien, The Department of Medicine, The Royal Melbourne Hospital, Royal Parade, Parkville, 3050, Victoria, Australia, Tel: + 613 8344 3260, Fax: + 6139348 2254,

E-mail: obrientj@unimelb.edu.au

Received 19 October 2004; revised 23 December 2004; accepted 20 January 2005

Online publication: 31 January 2005 at http://www.acnp.org/citations/ NPPO I 3 10504049//default.pdf
}

suggested a bidirectional relationship between epilepsy and depression when he wrote 'melancholics ordinarily become epileptics, and epileptics melancholics' (Lewis, 1934). Recently, there has been renewed interest in the possibility that depression and stress may act to enhance epileptogenesis (Karst et al, 1999). Many epilepsy patients and clinicians have the strong impression that psychological stress is a risk factor for the illness and provokes the onset of epilepsy (Frucht et al, 2000; Schmid-Schonbein, 1998). There is good evidence that seizure frequency in many patients with chronic epilepsy is aggravated by stress and can be reduced by psychological means (Schmid-Schonbein, 1998). Furthermore, epidemiological studies have suggested that depression is a risk factor for epilepsy onset (Hesdorffer et al, 2000).

One plausible neurobiological mechanism by which stress and depression could potentially enhance epileptogenesis is via an effect on the hypothalamic-pituitary-adrenal (HPA) axis. The normal structure and function of the HPA axis are tied intimately to the medial temporal lobe, with the 
amygdala and hippocampus playing key roles in HPA feedback control (Herman and Cullinan, 1997). This raises the possibility that the HPA axis may be dysfunctional in hippocampal sclerosis and MTLE. The stress mediator, corticotrophin-releasing hormone $(\mathrm{CRH})$, is present in these structures; although its functions there are not yet well understood, considerable evidence exists for a pivotal role for $\mathrm{CRH}$ in epileptogenesis in infancy and childhood (Baram and Hatalski, 1998). In a range of animal models, laboratory stressors and exposure to exogenous glucocorticoids result in structural and functional alterations in brain regions critically involved in MTLE, especially the hippocampus and amygdala (Gould et al, 2000; McEwen and Magarinos, 2001; Vyas et al, 2003). CRH and the HPA axis are centrally involved in these changes. In humans, trauma, stress, and pathological states with prolonged elevation of glucocorticoids (such as Cushing's syndrome and depression) are associated with diminished hippocampal volume on neuroimaging or at autopsy, with evidence of impaired hippocampal-associated memory on neuropsychological testing (Belanoff et al, 2001; Gurvits et al, 1996; MacQueen et al, 2003).

Few studies have directly addressed the possibility that stress (or stress mediators) affects epileptogenesis. Karst et al (1999) showed that high-dose corticosterone (CS) exposure (via a subcutaneous pellet releasing $100 \mathrm{mg} /$ day) in young rats resulted in an acceleration of hippocampal electrical kindling epileptogenesis compared to controls. However, the high pharmacological dose of CS used in this study is unlikely to equate to the physiological alterations seen in chronic stress and depression. Another study demonstrated that electrical amygdala kindling rates were accelerated in adrenalectomized rats when given low-dose CS replacement in their drinking water $(3 \mathrm{mg} / 100 \mathrm{ml}-$ enough to significantly elevate the blood CS levels) compared to rats given saline only (Edwards et al, 1999b). However, these results could be equally well explained by an inhibition of epileptogenesis in rats pathologically deficient in CS.

In this study, we investigated whether chronic low-dose CS supplementation in the drinking water ( $3 \mathrm{mg} /$ $100 \mathrm{ml}$ - approx. $4.5 \mathrm{mg} / \mathrm{kg} /$ day) accelerates amygdala electrical kindling in nonadrenalectomized rats. We also used histological methods to examine whether any observed enhancement of epileptogenesis was associated with increased hippocampal pyramidal cell loss. Quantitative pyramidal cell counts were performed using unbiased stereological methods in the ipsilateral hippocampal CA1 region, as this was the region where there is maximal pyramidal cell loss in patients with MTLE as well as in animal models (Engel Jr et al, 1997; McNamara and Wada, 1997).

\section{MATERIALS AND METHODS}

\section{Animals and Treatments}

Female nonepileptic Wistar rats aged 16-17 weeks from the Ludwig Institute of Cancer Research/Department of Surgery Royal Melbourne Hospital breeding colony were used. Female rats were chosen for use in this study because the known gender differences in the incidence of anxiety and depression in humans (Parker and Hadzi-Pavlovic, 2004). Rats were ovariectomized at the time of electrode implantation to remove the effects of fluctuations in sex hormone levels during the estrous cycle. All rats were allowed free access to water and rat chow and housed at $20^{\circ} \mathrm{C}$. Rats were randomly divided into two groups: one group was treated with CS in their drinking water $(3 \mathrm{mg} / 100 \mathrm{ml}$-approx. $4.5 \mathrm{mg} / \mathrm{kg} / \mathrm{day}, n=7)$, while the control group was given normal saline $(0.9 \% \mathrm{NaCl}, n=7)$. The estimate of CS received was based on dividing the water intake per day by the weight of the individual rat at that time. This dose of CS was chosen because it had been shown to elevate plasma CS levels into the physiological range in adrenalectomized rats (Edwards et al, 1999b) and, therefore, was felt to be appropriate to the situation that may exist in chronic stress states. Kindling stimulations were performed twice daily, and the time to reach the end point of five Class V seizures (ie fully kindled; Racine, 1972) compared between the groups. CS/control supplementation was commenced 2 days prior to the first electrical stimulation and continued until the animals were culled ( 2 weeks after becoming fully kindled). The animals were weighed weekly. The Ludwig Institute of Cancer Research/Department of Surgery Animal Ethics Committee approved all procedures (AEC\#23/03).

\section{Surgeries and Amygdala Kindling Procedures}

Rats underwent surgery 7 days prior to the start of the kindling stimulations. Rats were anesthetized with xylazine $(10 \mathrm{mg} / \mathrm{kg})$ and ketamine $(75 \mathrm{mg} / \mathrm{kg})$ intraperitoneally (i.p.). For the electrode implantations, a single midline incision was made over the scalp and five holes were drilled through the skull for extradural ground and reference electrodes (two) and for anchoring screws (three). Rats were then placed in a stereotactic head frame to insert a bipolar electrode into the left amygdala (AP: -3.0 ; ML: +5 relative to bregma and dorsoventral $-6.5 \mathrm{~mm}$ relative to dura). Dental cement was then applied to the skull to fix the electrodes in place. After recovery from surgery animals were placed in separate boxes for 7 days prior to commencement of the kindling stimulations.

The electrical kindling stimulations were performed twice a day with at least a 4 -h interval. The rats were stimulated via the bipolar electrodes using an Accupulser Pulse Generator/Stimulator (A310, World Precision Instruments, Sarasota, FL) connected to a battery-operated, optically isolated, constant stimulus isolator (A360, World Precision Instruments, Sarasota, FL). Stimulations consisted of a $1 \mathrm{~s}$ train of $1 \mathrm{~ms}$ biphasic square wave pulses at a frequency of $60 \mathrm{~Hz}$ with current intensity of $200 \mu \mathrm{A}$. Subsequent behavioral changes were observed and classified according to the Racine classification (Racine, 1972): Class I-facial clonus; Class II - head nodding; Class III — one limb jerking; Class IV-rearing; and Class V-falling. Stimulation was ceased after the rats had five Class V seizures. The behavioral class of the seizures was determined by direct observation of the animals by a single observer (TT), and then confirmed by review of the videotape by a second blinded observer (TOB). The brain activity was monitored and recorded using the EEG machine for $1 \mathrm{~min}$ prior to stimulation and $1 \mathrm{~min}$ following the cessation of the after-discharge. The length of 
the after-discharges on the EEG recordings was analyzed using EEG Profusion ${ }^{\mathrm{TM}}$ software (Compumedics, Melbourne, Australia).

\section{Brain Collection and Processing}

Rats were kept for 2 weeks once they reached the fully kindled state and continued to receive the CS or control supplemented water. Rats were then given an overdose of anesthetic (xylazine, $20 \mathrm{mg} / \mathrm{kg}$ ) and ketamine $(150 \mathrm{mg} / \mathrm{kg}$, i.p) and transcardially perfused with $150 \mathrm{ml} 0.1 \mathrm{M}$ phosphate-buffered saline (PBS, $\mathrm{pH} 7.4$ ) followed by $450 \mathrm{ml} 4 \%$ paraformaldehyde (PFA in 0.1 M PBS, pH 7.2). Rats were decapitated and the brain was removed and stored in $4 \%$ PFA for $4 \mathrm{~h}$, and then removed to a $20 \%$ sucrose solution (0.1 M PBS, pH 7.2) and kept for $48 \mathrm{~h}$ at $4{ }^{\circ} \mathrm{C}$. After $48 \mathrm{~h}$, the brains were snap frozen with liquid nitrogen. Molds were set deep into a plastic container filled with isopentane that was immersed in liquid nitrogen. The frozen brain was stored at $-70^{\circ} \mathrm{C}$.

\section{Serum CS Assays}

Transcardial blood samples $(0.3 \mathrm{ml})$ were taken from anesthetized animals using a heparinized syringe (100 U/ $\mathrm{ml}$ heparin in $0.9 \%$ saline) from the left ventricle, just prior to performance of the transcardial perfusion. Blood was spun down by centrifugation for $8 \mathrm{~min}$ at 12000 revolutions per minute. Plasma CS levels were measured by double antibody Corticosterone Radioimmunoassay (RIA) kit (MP Biomedicals). All samples were tested in duplicate.

\section{Histological Analysis}

In all, $20-\mu \mathrm{m}$ coronal cryostat sections were cut through the brain to include the entire hippocampal formation and amygdala. Every 25th section was mounted and stained with thionin $(0.1 \%)$ in acetate buffer for $30 \mathrm{~min}$, dehydrated, and coverslipped. Sections were examined to confirm the correct electrode placement in the amygdala complex.

In order to investigate whether the low-dose CS administration resulted in an enhancement of hippocampal neuronal cell loss, sections from the CS-treated rats and controls were first visually qualitatively compared for all regions. Secondly, a quantitative estimation of total neuronal number, density, and region volume was performed for the pyramidal cell layer of the ipsilateral CA1 region of the hippocampus. These cells were chosen for the quantification because previous quantitative stereological studies have shown they, along with those of the CA3 and dentate hilus region, are the cell types that are maximally decreased in rats having undergone amygdala kindling, with neuronal loss being detected after as few as three Class V seizures (Cavazos et al, 1994). Therefore, it would be anticipated that if the CS supplementation resulted in enhanced neuronal cell loss, it would be sensitively detected by quantification of the CA1 pyramidal neurons.

For the quantification, an unbiased stereological method was employed, using the optical fractionator (West et al, 1991), in which the number of CA1 neurons was systematically counted with the optical dissector technique
(Gunderson and Jensen, 1987) within a known fraction of the total CA1 hippocampal region. Neurons were counted under oil immersion with an Olympus microscope (BX50), which was fitted with an electronic microcator (Multicontrol, 2000) and a video camera and connected to a computer. Live microscope images were analyzed using the Complete Assisted Stereological Toolbox (CAST Grid, Olympus, Denmark) software. The volume of the CA1 region was estimated using the Cavalieri principle as described previously (Mallard et al, 2000). Measurements were performed by a single operator (TT) who was blinded to the treatment group of the animals.

\section{Statistical Analysis}

Data were analyzed with the software package Statistica ${ }^{\mathrm{TM}}$. The number of stimulations required to reach five Class $\mathrm{V}$ seizures, the primary end point of the study, was compared between CS-supplemented and control rats using Student's $t$-test. The length of the after-discharges was compared between the groups, using analysis of variance (ANOVA) for repeated measures, for the average of every 10 stimulations through to the maximum number of stimulations that any animal received (ie 150). For animals receiving fewer stimulations (ie attained five Class 5 seizure with fewer than 150 stimulations), the length of the afterdischarge for the final stimulation was extrapolated out for the remaining stimulation time points for this analysis. A more conservative analysis of the after-discharge lengths was also performed, utilizing only the number of stimulation points up to and including that which all animals were stimulated. The CA1 pyramidal cell counts $(N)$, volume $(V)$, and cell density $(D)$ estimations were compared between the groups using Student's $t$-test. A level of $p<0.05$ was defined as significant.

\section{RESULTS}

\section{CS Dose}

The rats drank an average of $43 \mathrm{ml}$ of water per day; this did not differ between those that drank CS or saline. This equated to an average daily dose of CS for the treatment group of $1.3 \mathrm{mg}$ ( or $4.5 \mathrm{mg} / \mathrm{kg}$ ) over the $6-12$ week treatment period (depending on the time to reach the fully kindled state).

\section{Kindling Stimulations}

Fewer stimulations were required in the CS-supplemented rats than in controls to reach full kindling (mean 32 vs 81, $p=0.03$, Student's $t$-test), the first Class V seizure (14 vs 57, $p=0.04$ ), the first seizure (6vs $36, p=0.05$ ), and the first convulsive seizure (11 vs $46, p=0.05$ ) (Figure 1 ). The length of the after-discharges was significantly greater in the CS-treated group $(p=0.03$, repeated measures ANOVA) (Figure 2). When a more conservative analysis of the length of after-discharges was performed, including only the data points where all animals were actually being stimulated (ie 20 stimulations), the difference between the groups was $p=0.005$ (repeated measures ANOVA). 


\section{Serum CS Levels}

The results of the serum CS assays from the transcardial punctures are summarized in Figure 3. The serum CS concentrations were $17 \%$ higher in the CS-treated animals than in the control animals, but this difference was not statistically significant (392 vs $336 \mathrm{ng} / \mathrm{ml}, p=0.46$, Student's $t$-test).

\section{Histological Analysis and Stereological Cell Number Estimations}

No qualitative differences were seen in any subregion of the hippocampus ipsilateral to the kindling electrodes between CS-supplemented and control rats. In quantitative studies, no significant differences were seen between the groups in

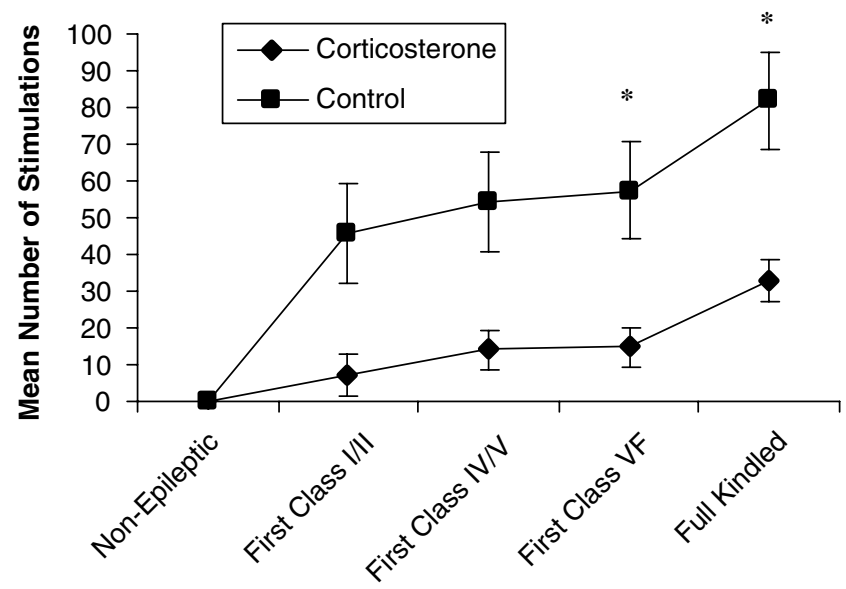

Figure I Plots mean number of stimulation $( \pm S E)$ required to reach the various kindling stages in CS-treated vs control rats ( $n=7$ both groups). * $p<0.05$ for the difference between the two groups (Student's $t$-test). the total number of CA1 pyramidal cells, density of the CA1 cells, or in the estimated volume of the CA1 region (all $p>0.05$, Student's $t$-test) (Table 1).

\section{DISCUSSION}

Depression occurs in approximately $45 \%$ of temporal lobe epilepsy patients (Altshuler et al, 1999), and there is evidence it is more common in MTLE than in other types of partial epilepsy (Quiske et al, 2000). This supports the view that there is a specific pathophysiological relationship between MTLE, depression, and chronic stress. Depression has usually been thought of as a complication of MTLE, that is, MTLE causes the depression. However, it is also possible that common factors give rise to both MTLE and depression (Jobe, 2003), or that depression itself contributes to the pathogenesis of MTLE (Hesdorffer et al, 2000).

The primary aim of this study was to test the hypothesis that chronic low-dose CS administration accelerates

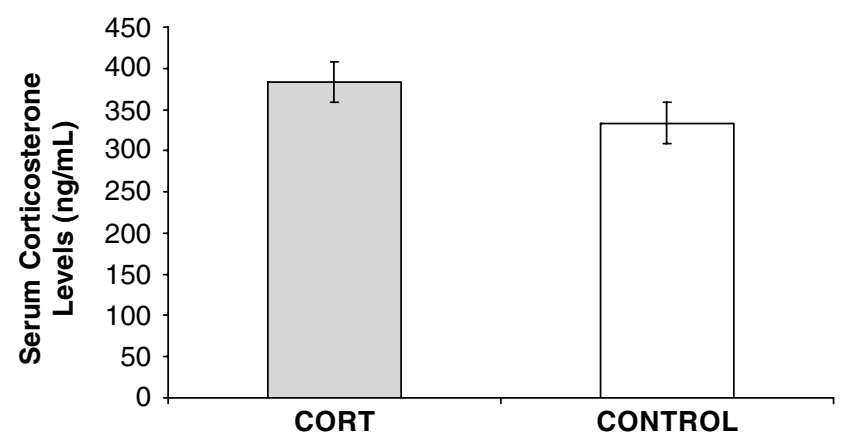

Figure 3 Mean serum CS levels from transcardial blood in CS-treated vs control rats. There was no significant difference between the groups $(p=0.46$, Student's $t$-test).

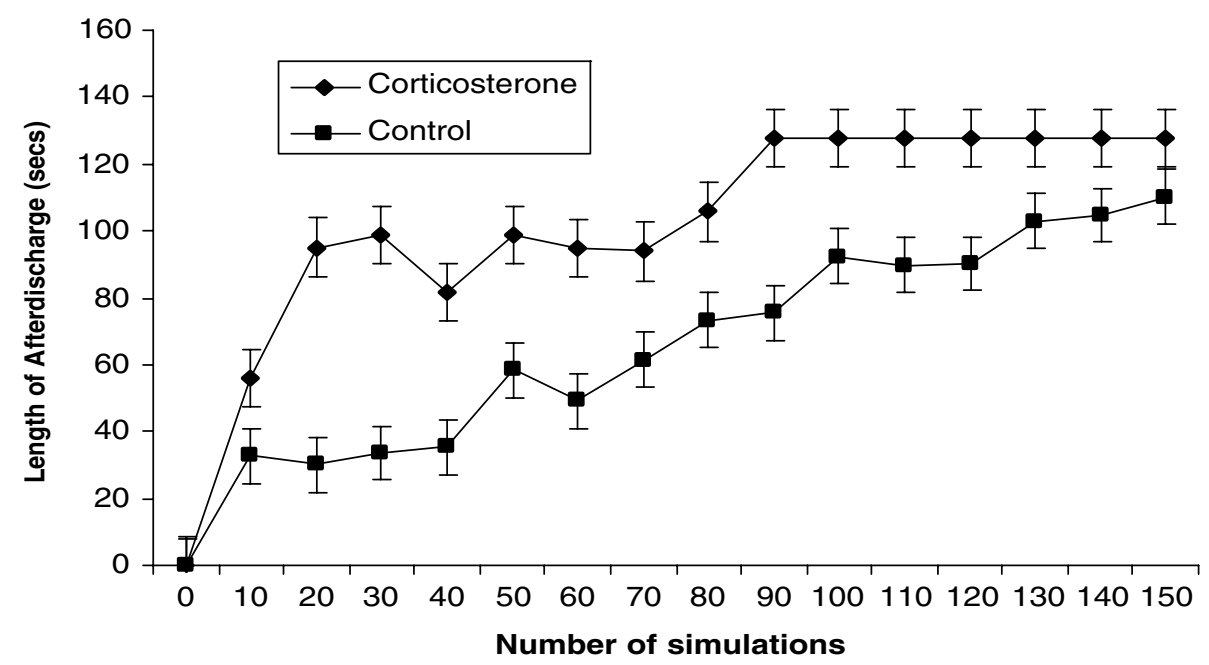

Figure 2 Plot of mean after-discharge length $( \pm S E)$ averaged over every 10 stimulations in CS-treated vs control rats $(n=7$ both groups). For animals receiving fewer stimulations (ie attained five Class 5 seizure with fewer than 150 stimulations), the length of the after-discharge for the final stimulation was extrapolated out for the remaining stimulation time points for this analysis. The difference between the groups was significant ( $p=0.03$, repeated measures ANOVA). An analysis only involving the data points, where all animals were actually being stimulated (ie 20 stimulations), showed an even more significant difference between the groups ( $p=0.005$, repeated measures ANOVA). 
Table I Total Number and Density of CAI Pyramidal Cells and Volume of the CAI Region in CS-Supplemented $(n=7)$ and Control $(n=7)$ Rats that Underwent Electrical Amygdala Kindling

Total cell number Volume $\left(\mathrm{mm}^{3}\right)$ Density $\left(\mathrm{n} / \mathrm{mm}^{3}\right)$

\begin{tabular}{cccc}
\hline CS & & & \\
Mean & $1.05 \times 10^{5}$ & 0.35 & $3.47 \times 10^{5}$ \\
Min & $0.59 \times 10^{5}$ & 0.14 & $1.92 \times 10^{5}$ \\
Max & $2.23 \times 10^{5}$ & 0.76 & $4.88 \times 10^{5}$ \\
& & & \\
Control & & & $3.99 \times 10^{5}$ \\
Mean & $1.04 \times 10^{5}$ & 0.32 & $1.92 \times 10^{5}$ \\
Min & $0.62 \times 10^{5}$ & 0.08 & $7.33 \times 10^{5}$ \\
Max & $2.53 \times 10^{6}$ & 0.79 & 0.54 \\
p-value & 0.97 & 0.83 & \\
\hline
\end{tabular}

epileptogenesis in the amygdala kindling rat model of MTLE (McNamara and Wada, 1997). This has been the most studied animal model of focal epilepsy and has practical advantages for this study over other models of MTLE, such as the postkainic acid and electrical status epilepticus models, in that the epileptogenesis occurs in a controlled and readily quantified manner. In addition, it is less 'destructive' than these other models, and therefore the epileptogenesis can be studied without the potential confounding effects of widespread, major tissue destruction in the brain (McNamara and Wada, 1997; Sarkisian, 2001).

Karst et al (1999) had previously reported that CS supplementation enhanced hippocampal electrical kindling. We used a different gender of rat (ovariectomized females rather than males), a different method of kindling epileptogenesis (amygdala rather than hippocampal), a different mode of administration of CS (via drinking water rather than subcutaneous pellet) and, probably most importantly, a lower dose of CS (approx. $4.5 \mathrm{mg} / \mathrm{kg} /$ day $v s$ $100 \mathrm{mg} /$ day). The dose used in the previous study was pharmacological rather than physiological, elevating the CS levels to four times those in the control treated rats, and therefore the results may not equate as well to the situation seen in patients with chronic stress and depression. The dose and method of administration of CS used in our study has previously been shown to result in accelerated rates of amygdala kindling in adrenalectomized rats compared with rats that drank only saline (Edwards et al, 1999b). We measured the effect of our CS treatment on serum levels of CS on blood taken from transcardial puncture (Figure 3). These data show that there was a mild (17\%) higher serum CS level in the CS-treated rats, but this difference did not attain statistical significance. These results are likely confounded by the acute stress effects of the anesthetic and the procedure, which would elevate CS levels in animals in which the HPA axis was not completely suppressed. This may, in at least part, explain the lack of significant difference in CS levels between the groups. However, importantly, the results confirm that the CS doses used in this study produced plasma levels that were within the physiological range, and appropriate to those that are seen in chronic stress in rats (Gomez et al, 1996).
Two other studies have shown that adrenalectomy inhibits epileptogenesis in the kainic acid (Lee et al, 1989) and kindling (Karst et al, 1997) rat models. The results of our study extend these findings by demonstrating that low dose of CS also accelerates amygdala kindling in nonadrenalectomized rats. This supports the hypothesis regarding MTLE that comorbid stress and depression, via chronic HPA activation and mild hypercortisolemia, may exacerbate the progressive epileptogenic nature of their disorder.

MTLE in humans is likely a multistep, neurodevelopmental disorder with vulnerability conferred in early life and emergence of the clinical disorder years later, typically in adolescence or young adulthood (Engel Jr et al, 1997). Even after the establishment of epilepsy, there is evidence that the repeated seizures result in ongoing neurobiological effects on the mesial temporal structures, thereby providing an opportunity for factors such as chronic stress and disturbances in HPA function to modulate these effects. Although not yet studied, it is plausible that stress and glucocorticoids may contribute to the memory deficits that commonly accompany human MTLE (Oxbury, 2000), which are often reported by patients to worsen over time as a cumulative effect of repeated seizures. In humans, physiological states, which feature prolonged elevation of glucocorticoids, are associated with evidence of impaired hippocampal-associated memory on neuropsychological testing (Belanoff et al, 2001). In addition, similar changes are seen after administration of glucocorticoids to healthy volunteers (Newcomer et al, 1999). The results of our study extend the spectrum of the neurobiological effects of glucocorticoids on brain function to an enhancement of epileptogenesis.

The mechanisms by which hypercortisolemia accelerates kindling-induced epileptogenesis are uncertain. Glucocorticoids are involved in the normal regulation of neuroplasticity and neurogenesis in the hippocampus (McEwen and Magarinos, 2001) including regulation of dentate gyrus granule cell turnover and development (Gould et al, 2000), which are profoundly abnormal in MTLE. The hippocampus and amygdala contain high densities of both Type I ('mineralocorticoid', MR) and Type II ('glucocorticoid', GR) glucocorticoid receptors. Stress-induced memory and learning impairments in a range of laboratory paradigms are mediated to a large extent through adrenal glucocorticoids (Oxbury, 2000). The exogenous administration of high, pharmacological, doses of glucocorticoids in a range of laboratory animals results in hippocampal structural change including atrophy of dendritic processes, death of pyramidal cells in the CA1 and CA3 regions, and inhibition of dentate granule cell neurogenesis (Gould et al, 2000; McEwen and Magarinos, 2001).

In this study, we found no differences between CSsupplemented and control rats in the stereological estimates of the CA1 pyramidal neuronal numbers, neuronal density, or CA1 volume in the hippocampus ipsilateral to the side of the stimulation (Table 1). This finding suggests that the acceleration of epileptogenesis in rats chronically exposed to low-dose CS is unlikely to be primarily due to glucocorticoid enhancement of neuronal excitotoxicity. We cannot exclude the possibility that subtle enhanced neuronal loss in the CS-supplemented rats may have occurred in cell types or brain regions other than the CA1 
pyramidal neuron region such as inhibitory interneurons within the hippocampus or neurons in extrahippocampal limbic structures such as the amygdala. However, it is the CA1 pyramidal neurons along with those in CA3 and the dentate hilus that have been shown by previous quantitative stereological studies to be decreased to the greatest extent in rats having undergone amygdala kindling (Cavazos et al, 1994). Importantly, it is these same cell types that are maximally lost in patients with chronic MTLE (Babb and Brown, 1987; Babb et al, 1984). Additionally, it was in the CA1 pyramidal neurons, in the study of Karst et al (1999), that significant neurophysiological changes (ie increased amplitude of population spike and of voltage-gated $\mathrm{Ca}^{2+}$ currents) were detected in brain slices taken from kindled rats treated with high-dose CS vs control kindled rats. Furthermore, in our study a careful qualitative examination of neuronal cell numbers in all hippocampal brain regions demonstrated no obvious differences between the CStreated and control animals.

The lack of neuronal cell loss demonstrated in low-dose CS-treated rats in this study suggest that the enhancement of amygdala kindling results from a functional alteration in the neurophysiological firing properties of limbic neurons and circuitries. It has been demonstrated that chronic stress in rats results in a loss of arborization, not just cell number, and this would not have been detected by our methods (McEwen and Magarinos, 1997). Glucocorticoids are also known to play an important role in the normal regulation of electrical activity in hippocampal circuitry and play an important role in long-term potentiation (LTP), long-term depression (LTD), and learning (de Kloet, 1991). LTP is thought to play a role in the development of kindling and epileptogenesis (McNamara and Wada, 1997). CS is also involved in modulating neuronal excitability (Joels and de Kloet, 1992). The study of Karst et al's demonstrated enduring electrophysiological changes on hippocampal slices taken after full kindling from CS-supplemented rats, even at a time when CS levels and hippocampal corticosteroid receptor mRNA levels were no longer elevated (Karst et al, 1999). Another recent study of restraint stress on hippocampal LTP in the rat found an association between stress and the occurrence of epileptic after-discharges in the CA3 region following high-frequency stimulation (Pavlides et al, 2002).

It should be noted that the rats in this study were ovarectomized females. Sex hormones, including estrogens, progesterones, and testosterone, have been shown to have important effects on seizures, and to influence kindling rates in rats (Edwards et al, 1999a, b). Estrogens have been shown to synergize with CS replacement in adrenalectomized rats (Edwards et al, 1999b). In this current study, the animals were castrated in order to test the effect of low-dose CS supplementation in nonadrenalectomized independent of any confounding effects of circulating sex hormones. Future studies could examine the effect of CS in noncastrated, nonadrenalectomized animals, as well the interactions of the various sex hormones. It is also acknowledged that this study could not determine the mechanism underlying the observed effect of CS, for example, whether the observed acceleration of kindling epileptogenesis was a direct effect of CS, or resulted from a secondary effect on another mediator.
In conclusion, the results from this study demonstrate that low-dose CS supplementation enhances epileptogenesis in the amygdala kindling rat model of MTLE. This provides support for the hypothesis that chronic mild hypercortisolemia, as a result of stress, anxiety, and/or depression, may facilitate the development and progression of epilepsy in patients with MTLE. The lack of a significant difference between CS-supplemented and CS-nonsupplemented animals in quantitative hippocampal CA1 cell estimations indicates that the mechanism for the enhanced epileptogenesis does not primarily involve CS enhancement of pyramidal neuronal loss.

\section{ACKNOWLEDGEMENTS}

We acknowledge the technical assistance of Ms Bianca Jupp and Mr Rink-Jan Lohman of the Department of Medicine, The University of Melbourne and of the staff at the Animal Facility of the Ludwig Institute for Cancer Research/ Department of Surgery. We do not have any conflicts of interest, financial or otherwise, that may potentially bias this work.

\section{REFERENCES}

Altshuler L, Rausch R DS, Kay J, Crandall P (1999). Temporal lobe epilepsy, temporal lobectomy, and major depression. J Neuropsychiatry Clin Neurosci 11: 436-443.

Babb T, Brown W (1987). Pathological findings in epilepsy. In: Engel J (ed). Surgical Treatment of the Epilepsies. Raven Press: New York.

Babb T, Pretorius W, Davenport C, Lieb J, Crandall P (1984). Temporal lobe volumetric cell densities in temporal lobe epilepsy. Epilepsia 25: 721-732.

Baram TZ, Hatalski CG (1998). Neuropeptide-mediated excitability: a key triggering mechanism for seizure generation in the developing brain. Trends Neurosci 21: 471-476.

Barry JJ, Lembke A, Huynh N (2001). Affective disorders in epilepsy. In: Ettinger A, Kanner A (eds). Psychiatric Issues in Epilepsy: A Practical Guide to Diagnosis and Treatment. Lippincott/Williams and Wilkins: Philadelphia. pp 45-71.

Belanoff JK, Gross K, Yager A, Schatzberg AF (2001). Corticosteroids and cognition. J Psychiatr Res 35: 127-145.

Cavazos JE, Indranil D, Sutula T (1994). Neuronal loss in limbic pathways by kindling: evidence for induction of hippocampal sclerosis by repeated brief seizures. J Neurosci 14: 3106-3121.

de Kloet ER (1991). Brain corticosteroid receptor balance and homeostatic control. Front Neuroendocrinol 12: 95-164.

Edwards HE, Burnham WM, MacLusky NJ (1999a). Testosterone and its metabolites affect afterdischarge thresholds and the development of amygdala kindled seizures. Brain Res 838: 151-157.

Edwards HE, Burnham WM, Mendonca A, Bowlby DA, MacLusky NJ (1999b). Steroid hormones affect limbic afterdischarge thresholds and kindling rates in adult female rats. Brain Res 838: $136-150$.

Engel Jr J, Williamson PD, Wieser H-G (1997). Mesial temporal lobe epilepsy. In: Engel Jr J, Pedley TA (eds). Epilepsy. A Comprehensive Textbook. Lippincott Raven: Philadelphia, PA. pp 2417-2426.

Frucht MM, Quigg M, Schwaner C, Fountain NB (2000). Distribution of seizure precipitants among epilepsy syndromes. Epilepsia 41: 1534-1539.

Gomez F, Lahmame A, de Kloet ER, Armario A (1996). Hypothalamic-pituitary-adrenal response to chronic stress in 
five inbred rat strains: differential responses are mainly located at the adrenocortical level. Neuroendocrinology 63: 327-337.

Gould E, Tanapat P, Rydel T, Hastings N (2000). Regulation of hippocampal neurogenesis in adulthood. Biol Psychiatry 48: 715-720.

Gunderson HJ, Jensen EB (1987). The efficiency of systematic sampling in stereology and its prediction. $J$ Microsc 147: 229-263.

Gurvits TV, Shenton ME, Hokama H, Ohta H, Lasko NB, Gilbertson MW et al (1996). Magnetic resonance imaging study of hippocampal volume in chronic, combat-related posttraumatic stress disorder. Biol Psychiatry 40: 1091-1099.

Herman J, Cullinan W (1997). Neurocircuitry of stress: central control of the hypothalamic-pituitary-adrenocortical axis. Trends Neurosci 20: 78-84.

Hesdorffer D, Hauser W, Annegers J, Cascino G (2000). Major depression is a risk factor for seizures in older adults. Ann Neurol 47: 246-249.

Jobe PC (2003). Common pathogenic mechanisms between depression and epilepsy: an experimental perspective. Epilepsy Behav 4(Suppl 3): S14-24.

Joels M, de Kloet ER (1992). Control of neuronal excitability by corticosteroid hormones. Trends Neurosci 15: 25-30.

Karst H, Bosma A, Hendriksen E, Kamphuis W, de Kloet ER, Joels M (1997). Effect of adrenalectomy in kindled rats. Neuroendocrinology 66: 348-359.

Karst H, de Kloet ER, Joëls M (1999). Episodic corticosterone treatment accelerates kindling epileptogenesis and triggers longterm changes in hippocampal CA1cells, in the fully kindled state. Eur J Neurosci 11: 887-898.

Lambert MV, Robertson MM (1999). Depression in epilepsy: etiology, phenomenology, and treatment. Epilepsia 40: S21-47.

Lee PH, Grimes L, Hong JS (1989). Glucocorticoids potentiate kainic acid-induced seizures and wet dog shakes. Brain Res 480: 322-325.

Lewis A (1934). Melancholia: a historical review. J Mental Sci 80: $1-42$.

MacQueen GM, Campbell S, McEwen BS, Macdonald K, Amano S, Joffe RT et al (2003). Course of illness, hippocampal function, and hippocampal volume in major depression. Proc Natl Acad Sci USA 100: 1387-1392.

Mallard C, Loeliger M, Copolov D, Rees S (2000). Reduced number of neurons in the hippocampus and the cerebellum in the postnatal guinea-pig following intrauterine growth-restriction. Neuroscience 100: 327-333.
McEwen BS, Magarinos AM (1997). Stress effects on morphology and function of the hippocampus. Ann NY Acad Sci 821: 271-284.

McEwen BS, Magarinos AM (2001). Stress and hippocampal plasticity: implications for the pathophysiology of affective disorders. Hum Psychopharmacol 16: S7-S19.

McNamara JO, Wada JA (1997). Kindling model. In: Engel Jr J, Pedley TA (eds). Epilepsy: A Comprehensive Textbook. Lippincott Raven: Philadelphia, PA. pp 419-425.

Newcomer JW, Selke G, Melson AK, Hershey T, Craft S, Richards K et al (1999). Decreased memory performance in healthy humans induced by stress-level cortisol treatment. Arch Gen Psychiatry 56: $527-533$

Oxbury SM (2000). Neuropsychological deficits in temporal lobe epilepsy. In: Oxbury J, Polkey CE, Duchowny M (eds). Intractable Focal Epilepsy. WB Saunders: London. pp 377-391.

Parker G, Hadzi-Pavlovic D (2004). Is the female preponderance in major depression secondary to a gender difference in specific anxiety disorders? Psychol Med 34: 461-470.

Pavlides C, Nivon LG, McEwen BS (2002). Effects of chronic stress on hippocampal long-term potentiation. Hippocampus 12: 245-257.

Quiske A, Helmstaedter C, Lux S, Elger CE (2000). Depression in patients with temporal lobe epilepsy is related to mesial temporal sclerosis. Epilepsy Res 39: 121-125.

Racine RJ (1972). Modification of seizure activity by electrical stimulation. II. Motor seizures. Electroencephalogr Clin Neurophysiol 32: 281-294.

Ring HA, Trimble MR (1993). Depression in epilepsy. In: Starkstein SE, Robertson RG (eds). Depression in Neurologic Disease. Johns Hopkins University Press: Baltimore, MD. pp 63-83.

Sarkisian MR (2001). Overview of the current animal models for human seizure and epileptic disorders. Epilepsy Behav 2: 201-216.

Schmid-Schonbein C (1998). Improvement of seizure control by psychological methods in patients with intractable epilepsies. Seizure 7: 261-270.

Vyas A, Bernal S, Chattarji S (2003). Effects of chronic stress on dendritic arborization in the central and extended amygdala. Brain Res 965: 290-294.

West MJ, Slomianka L, Gunderson HJ (1991). Unbiased stereological estimation of the total number of neurons in the subdivisions of the rat hippocampus using the optical fractionator. Anat Rec 231: 482-497. 